\title{
Impact of Compliance with a Sepsis Resuscitation Bundle in a Portuguese Emergency Department
}

\author{
Impacto do Cumprimento da Bundle de Ressuscitação \\ da Sépsis num Serviço de Urgência Português
}

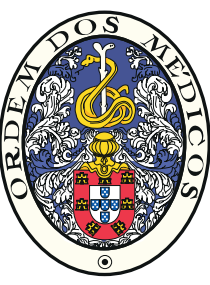

\author{
João M. CARVAS $\triangle^{1}$, Gustavo MONTANHA ${ }^{1}$, Cátia CANELAS ${ }^{1}$, Carlos SILVA ${ }^{2}$, Francisco ESTEVES ${ }^{1}$ \\ Acta Med Port 2016 Feb;29(2):88-94 - http://dx.doi.org/10.20344/amp.6998
}

\section{ABSTRACT}

Introduction: Severe sepsis and septic shock are common conditions with high levels of morbi-mortality surpassing those of coronary heart disease or stroke. The reality of hospital treated sepsis is largely unknown outside of the intensive care unit. We therefore aimed to evaluate the level of compliance with the Surviving Sepsis Campaign 6-hour bundle in a Portuguese emergency department and to relate it to the patient clinical outcomes.

Material and Methods: We conducted a retrospective, observational cohort study with 178 severe sepsis/septic shock patients admitted to the intensive and intermediate care unit between January $1^{\text {st }} 2012$ and December $31^{\text {st }} 2012$.

Results: In the study, period septic shock was diagnosed in 100 patients (56.2\%) and severe sepsis in 78 patients (43.8\%). Compliance with the sepsis bundle was: (1) $62.9 \%$ for lactate measurement; (2) $62.9 \%$ for blood cultures before antibiotics; (3) $41.6 \%$ for antibiotics in the first 3 hours; (4) $76.4 \%$ for fluid administration; (5) $25 \%$ for vasopressor administration; (6) $37 \%$ for central venous pressure measurement and (7) 39\% for central venous oxygen saturation measurement. Full compliance was observed in $22 \%$ of the patients. The individual bundle measure - Blood cultures before antibiotics - was significantly associated with a decreased risk of both intensive care unit mortality and 28-day mortality. There was also a trend for an inverse correlation between increased compliance with the full bundle and the intensive care unit and 28-days hospital mortality.

Discussion: There was a low compliance with the Surviving Sepsis Campaign 6-hour bundle, a result that replicates the findings in similar international studies. The explanation is complex but it may include the lack of institutional quality monitoring in the emergency department.

Conclusions: The compliance with a sepsis resuscitation bundle starting in the emergency department was positively associated with the outcomes of the septic patients. Nonetheless the bundle was unreliably performed.

Keywords: Emergency Service, Hospital; Guideline Adherence; Portugal; Sepsis; Shock, Septic.

\section{RESUMO}

Introdução: A sépsis severa e o choque sético são entidades clínicas frequentes com elevada morbi-mortalidade que superam os da doença cardíaca coronária ou do acidente vascular cerebral. A realidade da sépsis tratada no hospital fora das unidades de cuidados intensivos é amplamente desconhecida. Pretende-se neste trabalho estimar o cumprimento da bundle das 6-horas da Surviving Sepsis Campaign num serviço de urgência português e os resultados clínicos dos doentes.

Material e Métodos: Estudo retrospetivo, observacional de coorte com 178 pacientes com sépsis severa/choque sético internados na unidade de cuidados intensivos e intermédios entre 1 de Janeiro de 2012 e 31 de Dezembro de 2012.

Resultados: Durante o período estudado foi diagnosticado choque sético em 100 pacientes $(56,2 \%)$ e sépsis severa em 78 pacientes (43,8\%). O cumprimento com a bundle foi: (1) 62,9\% para a medição de lactatos; (2) 62,9\% para a colheita hemoculturas antes da antibioterapia; (3) 41,6\% para a administração de antibióticos nas primeiras 3 horas; (4) 76,4\% para a administração de fluidos; (5) 25\% para a administração de vasopressores; (6) 37\% for medição da pressão venosa central; (7) 39\% para a medição da saturação venosa central de oxigénio. O cumprimento de todas as medidas foi observado em $22 \%$ dos pacientes. A medida 'colheita hemoculturas antes da antibioterapia' esteve significativamente associada a um menor risco de mortalidade na unidade de cuidados intensivos e aos 28 dias. Também se verificou uma tendência para uma correlação inversa entre cumprimento crescente da bundle e a mortalidade na unidade de cuidados intensivos e aos 28 dias.

Discussão: A baixa adesão à bundle das 6-horas da Surviving Sepsis Campaign é um resultado que replica o de estudos internacionais semelhantes. A explicação para este fenómeno é complexa mas pode incluir a falta de monitorização da qualidade dos cuidados no serviço de urgência.

Conclusões: O cumprimento da bundle de ressuscitação da sépsis desde a chegada do doente ao serviço de urgência está associado positivamente com os resultados clínicos do paciente sético. O cumprimento das medidas não foi no entanto muito elevado.

Palavras-chave: Adesão às Directrizes; Choque Sético; Portugal; Sépsis; Serviço Urgência Hospitalar.

\section{INTRODUCTION}

Sepsis is a clinical syndrome that represents the systemic inflammatory response of the body to an infection and can have deleterious consequences such as organ dysfunction (severe sepsis) and/or fluid-refractory hypotension (septic shock). ${ }^{1}$ The European Sepsis Occurrence in Acutely III
Patients (SOAP) study, that included patients admitted for severe sepsis/septic shock in 198 multinational intensive care units, estimated mortality rates of $32 \%$ for severe sepsis and $54 \%$ for septic shock. ${ }^{2}$ In Portugal the hospital mortality for sepsis originating from a community acquired

\footnotetext{
1. Centro Hospitalar de Trás-os-Montes e Alto Douro, EPE. Vila Real. Portugal.

2. Sciences School. Universidade do Minho. Guimarães. Portugal

$\bowtie$ Autor correspondente: João M. Carvas. jmcarvas@gmail.com

Recebido: 13 de setembro de 2015 - Aceite: 16 de dezembro de 2015 | Copyright $@$ Ordem dos Médicos 2016
} 
infection (CAI) was estimated as $38 \%$ in one study. ${ }^{3}$ The Surviving Sepsis Campaign (SSC) movement was created in 2002 as a joint effort of the Society of Critical Care Medicine and the European Society of Intensive Care Medicine aimed at improving the awareness but also the management and outcomes of the septic patient. In 2004 the first SSC evidence-based clinical guidelines were published. ${ }^{4,5}$ Sepsis is a time critical illness, requiring early identification and prompt intervention in order to improve outcomes. The 2008 guidelines include a 6-hour clinical bundle, also known as the 'resuscitation bundle' and a 24hour bundle, the 'management bundle'. The resuscitation bundle includes clinical measures to be taken in the first 6-hours after patient arrives to a medical center. They include blood lactate measurement, but also the early blood culture and broad-spectrum antibiotics administration, and the tackling hemodynamic derangements. ${ }^{6}$ The 24-hour bundle was never consensual and was intended specifically for the intensive care environment.

Centro Hospitalar de Trás-os-Montes e Alto Douro, EPE (CHTMAD) is part of the 8 Portuguese National Health Service (NHS) hospitals that implemented these norms in 2010 (green line of sepsis). ${ }^{7}$ Following the implementation of the SSC guidelines in 2004 and until 2009 the hospital mortality from septic shock has decreased $25 \%$ in the ICU of this hospital. ${ }^{8}$ The outcome measurements should not hinder the importance of measuring the implementation of the measures themselves (process measures). ${ }^{9,10}$ The compliance with the SSC guidelines in CHTMAD, especially in the emergency department (ED) and in the clinical wards remains unknown, as does its contribution to the improved outcomes of patients.

\section{MATERIAL AND METHODS \\ Patients}

Patients admitted to the Intensive and Intermediate Care Unit (IICU) of CHTMAD between 1 January 2012 and 31 December 2012, with the diagnosis criteria of severe sepsis or septic shock, originating from a CAI, were identified retrospectively from the IICU clinical records. Severe sepsis was defined as the presence of signs and symptoms of infection with at least one organ dysfunction, and septic shock as fluid refractory hypotension (MAP $<65 \mathrm{mmHg}$ ) requiring the administration of a vasopressor agent. ${ }^{1}$ The study design was approved by the local Health Research and Ethics Committee. The need for informed consent was waived due to the observational character of the study. This was a descriptive, retrospective, cohort study.

\section{Data collection}

All data the data was collected by a research fellow not involved in the medical care of the patients. The patients' hospital records were thoroughly analyzed to extract data relative to the compliance with specific SSC bundle for that episode. Data extracted included the time of admission to ED or time of the sepsis diagnosis, and also the time for the each relevant clinical gesture. Data regarding the dates of patient discharge from the hospital or of patient death were also collected. For comparative reasons, time zero was defined as time of admission to the ED. Other data like patient comorbidities and disease severity scores were collected from the IICU patient charts.

\section{Sepsis bundles and compliance}

According to the 2008 SSC guidelines for the management of severe sepsis and septic shock, all patients should receive a number of measures in the first 6 hours

Table 1 - The 2008 Surviving Sepsis Campaign 6-hour and 24-hour sepsis bundles

\footnotetext{
Sepsis resuscitation bundle (6 hour bundle)

1. Serum lactate measured;

2. Blood cultures obtained before antibiotic administration;

3. Broad-spectrum antibiotics administered within 3 hours;

4. In the event oh hypotension and/or lactate $\geq 4 \mathrm{mmol} / \mathrm{L}$;
}

4.1. Deliver an initial minimum of $20 \mathrm{~mL} / \mathrm{kg}$ of crystalloid (or colloid equivalent);

4.2. Apply vasopressor for hypotension not responding to initial fluid resuscitation to maintain mean arterial pressure $>65 \mathrm{mmHg}$;

5. In the event of persistent hypotension and/or lactate $\geq 4 \mathrm{mmol} / \mathrm{L}$;

5.1. Achieve central venous pressure (CVP) of $\geq 8 \mathrm{mmHg}$;

5.2. Achieve central venous oxygen saturation $\left(\mathrm{ScVO}_{2}\right)$ of $\geq 70 \%$.

Sepsis management bundle (24 hour bundle)

1. Low-dose steroid administered for septic shock in accordance with ICU policy;

2. Drotrecogin alpha (activated) administered in accordance with ICU policy;

3. Glucose control maintained greater than lower limit of normal but < $150 \mathrm{mg} / \mathrm{dL}$;

4. Inspiratory plateau pressures maintained $<30 \mathrm{cmH}_{2} \mathrm{O}$ for mechanically ventilated patients. 
after admission to the ED, known together as the 6-hour bundle or resuscitation bundle (Table 1). The measure was counted as valid if it was executed in the predetermined time interval (first six hours). For antibiotic administration, time for compliance was three hours and not six hours. The total score was divided in three categories: non-compliant (NC, 0 - 1 measures); partially compliant (PC, 2 - 3 measures for the severe sepsis group and 2-4 measures for the septic shock group) and fully compliant (FC, four measures for the severe sepsis group and five measures for the septic shock group). The clinical measures vasopressor administration, central venous pressure (CVP) measurement and central venous oxygen saturation $\left(\mathrm{ScvO}_{2}\right)$ measurement were only counted when the patient was eligible for that action (SC diagnosis). The 24 hour bundle analysis (management bundle) was not in the scope of this work.

\section{Statistics}

In the descriptive analysis, Pearson chi-squared test was used for categorical variables. Mann-Whitney $U$ test was used for non-normal distributed variables. To compare multiple groups the Kruskal-Wallis test was used. Relative risks were calculated for dichotomous outcomes. $p<0.05$ was designated as significant. The statistical analysis was performed in SPSS ${ }^{\circledR} 16$ (SPSS Inc, Chicago, IL, USA).

\section{RESULTS}

During the study period the IICU admitted 727 patients, 224 of which for severe sepsis/septic shock from a CAI. For different reasons including the non-fulfillment of diagnostic criteria or because of missing or incorrectly registered data, 46 cases were excluded from our analysis. Severe sepsis was diagnosed in $43.8 \%(n=78)$, and septic shock in $56.2 \%$ $(n=100)$. The global IICU mortality for septic patients was $14 \%(n=25)$ and the hospital mortality was $20.2 \%$ (28 day mortality, $\mathrm{n}=36$ ).
The septic patient's cohort was similar to the global group of patients entering IICU regarding age (69 years, interquartile range (IQR) 51 - 77 years), gender $(65.0 \%$ males, $34.8 \%$ females), hospital stay time (15 days, IQR 9 - 25 days) and number of comorbidities. These included obesity, diabetes, high blood pressure, chronic obstructive pulmonary disease, chronic kidney disease, congestive heart failure, chronic alcoholic liver disease and cancer. Nevertheless there was a significant difference regarding IICU stay time ( 5 days, IQR 3 - 9 days in the sepsis cohort vs 3 days, IQR 1 - 6 days in the global cohort, $p<0.001)$, APACHEII score (19, IQR 15 - 25 in the sepsis cohort vs 15 , IQR 10 - 21 in the global cohort, $p<0.001)$, SAPSII score (42, IQR 32 - 52 in the sepsis cohort vs 35, IQR 24 - 47 in the global cohort, $p<0.001)$ and SOFA score at admission (7, IQR 4 - 10 in the sepsis cohort vs 4, IQR 2 - 8 in the global cohort, $p<0.001)$, and SOFA score at discharge (3, IQR 2 - 4 in the sepsis cohort vs 2, IQR 1 - 4 in the global cohort, $p<0.001$ ).

The majority of patients originated from the ED of CHTMAD reference hospital (Vila Real, 72\%) and from other neighbor hospitals (Chaves, $12.9 \%$ and Lamego, $13.8 \%$ ).

The compliance with the individual measures in the resuscitation bundle was variable, but it was lower for the three procedures specific for the septic shock patient (Fig. 1). Compliance with all the measures of the bundle (fully compliant group, FC) was observed in 40 patients (22\%). The partially compliant group (PC) included 97 patients and the non-compliant (NC) 41 patients. According to the compliance group the hospital mortality and the IICU mortality showed marked variations. Hospital mortality was higher in the NC group (NC $29.3 \%$ vs PC $18.6 \%$ vs FC $15.0 \%$, ns). The same trend was also seen for the IICU mortality with the highest values observed in the NC group (NC $19.5 \%$ vs PC $12.4 \%$ vs FC 12.5, ns).

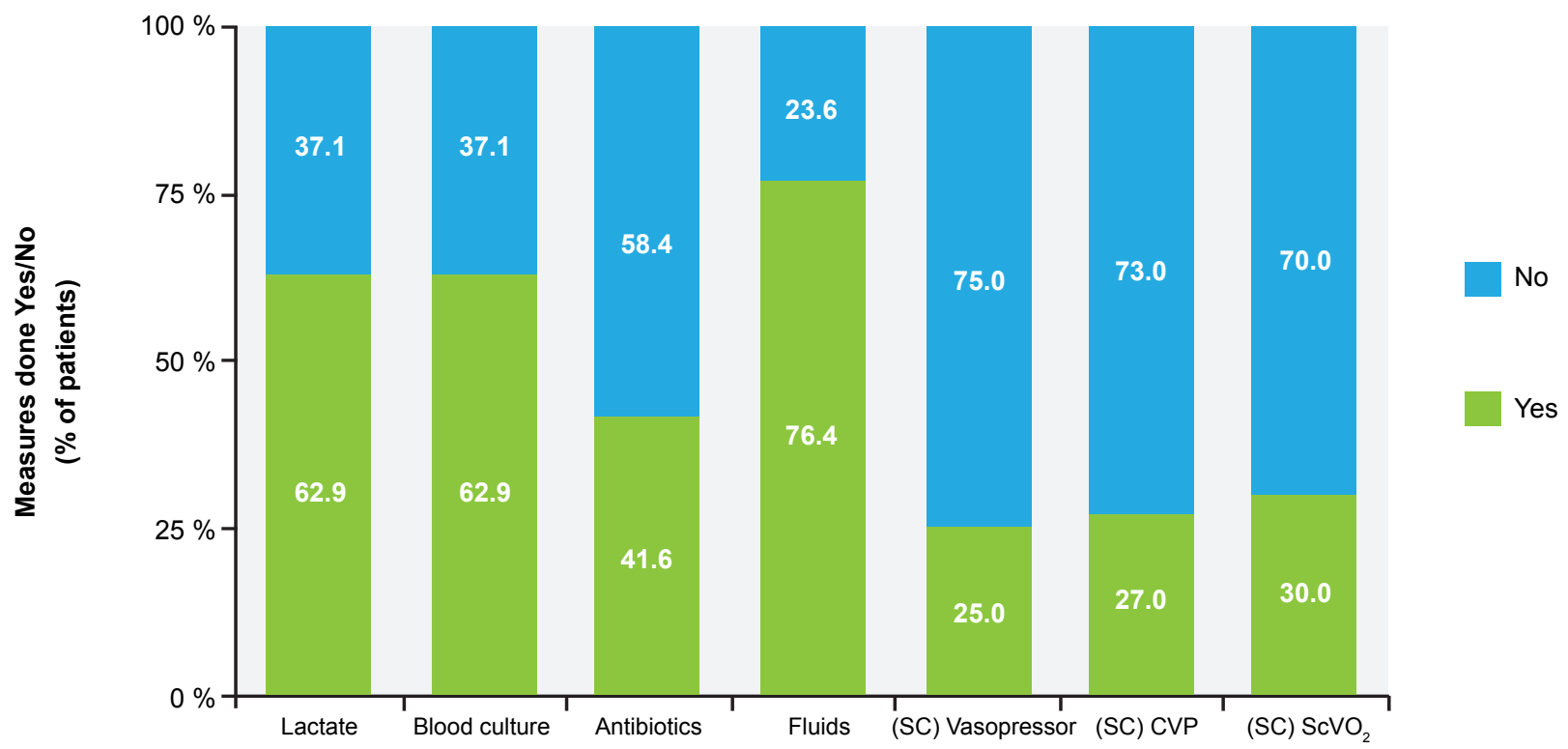

Figure 1 - Compliance with individual bundle measures ( $\%$ of patients)

SC: septic shock; CVP: central venous pressure. 
Nonetheless these differences did not reach statistical significance (Fig. 2). The FC group showed a trend for decreased hospital stay time, and a decrease in severity score APACHII arriving to the IICU, when compared to the NC group (Table 2).

The CAl origin was different between the 3 groups of compliance, with the FC group having a higher proportion of respiratory infections (84\%), followed by abdominal $(8 \%)$ and urogynecological $(8 \%)$ infections. The same trend was observed in the $\mathrm{PC}$ group regarding respiratory infections (54.5\%), abdominal infections (26.8\%) and urogynecological infections $(9 \%)$. In the NC the origin of CAl was homogenously distributed between respiratory infections (41.5\%) and abdominal infections (41.5\%).

The only individual bundle measure that was significantly associated to a decrease in the 28-day hospital mortality was 'collecting blood cultures before antibiotics' (relative risk $(\mathrm{RR})=0.42,95 \%$ confidence interval $(\mathrm{Cl})=0.23$ to $0.76)$. This measure was also significantly associated with a decrease in IICU mortality $(\mathrm{RR}=0.393,95 \% \mathrm{Cl}=0.19$ 0.82) (Table 3).

\section{DISCUSSION}

In this study, during the analyzed period, only $22 \%$ of the patients with severe sepsis or septic shock received the full resuscitation bundle as recommended by the 2008 SSC guidelines. Interestingly, the 'green line of sepsis' was only activated for 9 patients (5.1\%), implying that some of the patients received the full bundle even though the 'green line' was not activated. This data is in agreement with the only Portuguese study analyzing sepsis bundles implementation. They found an even lower adherence to the full bundle $(12 \%) .{ }^{11}$ The low compliance to the resuscitation bundle, but also the 'green line' implementation can have multiple reasons including a low level of awareness of the guidelines by the health professional and/or organizational difficulties hindering their correct implementation. A questionnairebased descriptive study in two national hospitals, evaluated sepsis identification and management skills among health workers, and showed a high percentage of correct answers (particularly by medical doctors) but, nonetheless, a low implementation of the 'green line of sepsis' in the emergency department (EDs). ${ }^{12}$ Another study in Spanish hospitals, showed an improvement in the compliance with the SSC guidelines after an educational program was set in place. Nonetheless, one year after the program ended, the compliance had decreased to the original low levels. ${ }^{13}$ These results indicate that the best care for the septic patient demands a continuous effort by the health institutions and professionals in continuous education but also, most importantly, in quality monitoring. The identification of SS/SC demands a high degree of awareness and solid knowledge among individual health professional but also among the institution itself. ${ }^{14}$ For example, efforts must be made so that all the necessary materials (blood culture bottles, first-line antibiotics) are always immediately available in the ED. The low adherence to the SC specific measures (vasopressor administration; CVP and $\mathrm{ScvO} 2$ measurement) is probably explained by the need of specialized professionals for the placing of central venous catheters. A more close interaction between emergency and intensive care health-workers would be useful in this regard. ${ }^{14}$

The introduction of the bundles and guidelines had a tremendous impact in critical patients with cardiac arrest, stroke and pneumonia for example. ${ }^{15}$ Following the publication of the SSC guidelines in 2004, the SSC organization demonstrated that their implementation, through multiple strategies, decreased mortality regardless

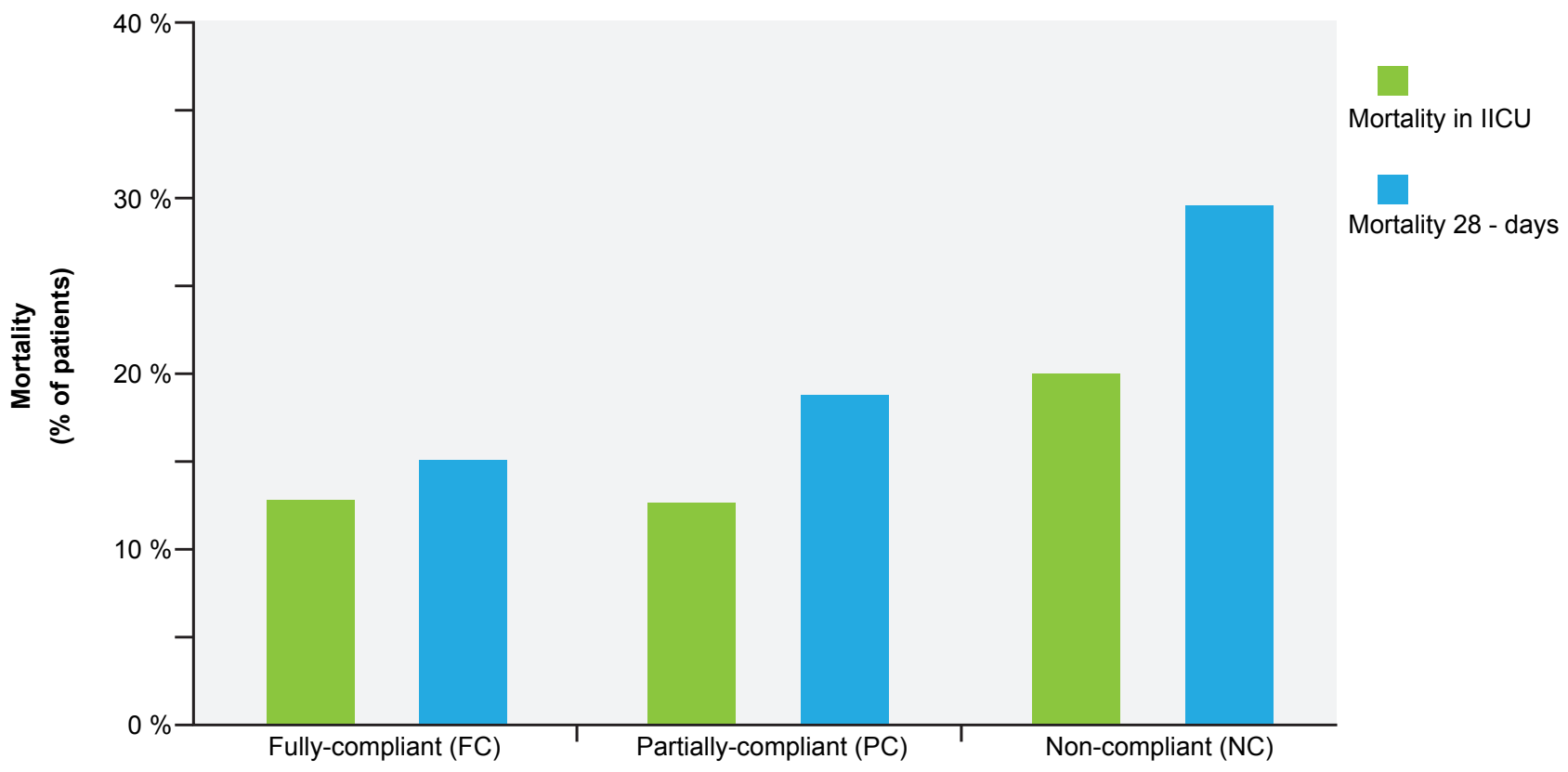

Figure 2 - Compliance with the 6-hour sepsis bundle and IICU and 28 days hospital mortality 
Table 2 - Patient demographic and clinical parameters according to the surviving bundle compliance group

\begin{tabular}{|c|c|c|c|c|}
\hline Parameters & Non-compliant & Partially-compliant & Fully-compliant & $p$ value \\
\hline & $n=41$ & $\mathrm{n}=97$ & $n=40$ & \\
\hline Age (years), median (IQR) & $69(53-79)$ & $69(51-76)$ & $69.5(51-75)$ & $\mathrm{ns}^{*}$ \\
\hline Septic shock, n (\%) & $21(51.2)$ & $53(54.6)$ & $26(65.0)$ & $\mathrm{ns}^{\#}$ \\
\hline IICU stay (days), median (IQR) & $4(3-11)$ & $5(3-9)$ & $5(2-9)$ & $\mathrm{ns}^{*}$ \\
\hline Hospital stay (days), median (IQR) & $15(9-24)$ & $16(9-27)$ & $13.5(7-20)$ & $\mathrm{ns}^{*}$ \\
\hline \multicolumn{5}{|l|}{ Comorbidities, n (\%) } \\
\hline 0 & $2(4.9)$ & $9(9.3)$ & $3(7.5)$ & $\mathrm{ns}^{\#}$ \\
\hline 1 & $6(14.6)$ & $17(17.5)$ & $9(22.5)$ & \\
\hline 2 & $8(19.5)$ & $18(18.6)$ & $9(22.5)$ & \\
\hline 3 & $7(17.1)$ & $24(24.7)$ & $8(20.0)$ & \\
\hline$>3$ & $18(43.9)$ & $29(29.9)$ & $11(27.5)$ & \\
\hline APACHE II, median (IQR) & $20(13-28)$ & $19(16-25)$ & $18(15-23.5)$ & $\mathrm{ns}^{*}$ \\
\hline SAPS II, median (IQR) & $44(34-58)$ & $42(32-52)$ & $43(31-50)$ & $\mathrm{ns}^{*}$ \\
\hline SAPS III, median (IQR) & $65(47-56)$ & $62(53-74.75)$ & $62(54.5-75)$ & $\mathrm{ns}^{*}$ \\
\hline SOFA_0, median (IQR) & $7(4-10)$ & $7(4-10)$ & $7(5-9)$ & $\mathrm{ns}^{*}$ \\
\hline SOFA_s, median (IQR) & $3(2-6)$ & $2(2-4)$ & $3(2-4)$ & $\mathrm{ns}^{*}$ \\
\hline
\end{tabular}

IICU: Intensive and Intermediate Care Unit; APACHE II: acute physiology and chronic health evaluation II score; SAPS II: simplified acute physiology score II score; sequential organ failure assessment score, at admission (SOFA_0) and at discharge from IICU (SOFA_s). ns: non significant; * Pearson chi-squared test; \# Kruskal Wallis test.

of the size of the institutions. ${ }^{16}$ The SSC published the results from a multinational study (15 022 patients, 165 sites, across 30 countries) analyzing the results of their global program where they report a reduction in mortality from $37.0 \%$ to $30.8 \%$ after the implementation of the 6 -hour bundle $^{16}$. In a prospective observational study, Gao et al showed that the compliance with the SSC6 was associated with a more than two-fold decrease in hospital mortality (49\% to $23 \%) .{ }^{17}$ Nonetheless, many authors have found very low compliance rates in their institutions ${ }^{16}$.

In our study, the patients which had full compliance with the resuscitation bundle (FC group) when compared with patients that received none or one of the bundle individual measures (NC group), had a $50 \%$ reduction in the 28 days hospital mortality ( $15 \%$ vs $29.3 \%$ respectively). This trend didn't reach statistical significance though probably because of insufficient number of patients in our study or due to the data gathering methodology. The Portuguese community-acquired sepsis study (SACiUCI) reported an improvement in mortality with the full completion of the sepsis resuscitation bundle, even though they had a low compliance with the full bundle. ${ }^{11}$ Our results support other studies where such reductions in mortality were found. ${ }^{17,19}$

When comparing individual bundle measures with the IICU and 28-day hospital mortality only one SSC6 measure was significantly related to a decreased relative risk in mortality: 'blood cultures collection before antibiotics'. The SSC recommends that two blood samples should be collected before the administration of antibiotics. This recommendation stems from work from the 1980s where a near $100 \%$ sensitivity for the detection of bacteraemia was determined, when two blood samples were collected manually. ${ }^{20}$ When performed judiciously this action allows for more rapid de-escalation and more targeted antimicrobial therapy, reducing the risks for secondary infection. In a landmark work, Kumar and colleagues determined that for each hour of delay to the administration of a large spectrum antibiotic the mortality raised $7.6 \% .{ }^{21}$ This reminds us that sample collection should never delay empirical antibiotic administration.

'Time zero' (t0) is the time point that determines in part the compliance/non-compliance with the bundles. We defined t0 as the time of admission to the ED (ED patients). Some authors use the 'time of diagnosis' as t0, that is, the time when hypotension and/or elevated blood lactate ( $\geq 4$ $\mathrm{mmol} / \mathrm{L}$ ) are identified. This decision significantly changes the levels of compliance with the bundles. In our study it decreased the number of the patients in the fully-compliant (FC) group, and it abolished statistically significant mortality results (data not shown). Nonetheless we consider that this t0 choice (arrival to the ED) in the patient best care interest. The choice of other definitions of to might grant a false sense of safety to heath care workers. ${ }^{22}$

The FC group had also a trend for less severe disease when compared with the NC group, with lower APACH II and SAPS II scores, although it had a higher fraction of SC patients. These results didn't reach statistical significance though. 
Table 3 - Relative risk for IICU and 28-day mortality for each action of the bundle completed

\begin{tabular}{|c|c|c|}
\hline Tested parameters & RR $(95 \% \mathrm{Cl})$ & $p$ value \\
\hline \multicolumn{3}{|l|}{ IICU mortality } \\
\hline Non-compliant versus Fully-compliant & $1.56(0.56-4.37)$ & ns \\
\hline Partially-compliant versus Fully-compliant & $1.01(0.38-2.68)$ & ns \\
\hline Lactate measurement; & $1.05(0.44-2.55)$ & ns \\
\hline Collect blood for hemocultures before antibiotics; & $0.393(0.19-0.82)$ & 0.01 \\
\hline Broad spectrum antibiotics administration (first 3-h); & $0.79(0.37-1.69)$ & ns \\
\hline Fluids (20 - $30 \mathrm{~mL} / \mathrm{kg}$ of crystalloids or equivalent) & $0.79(0.36-1.77)$ & ns \\
\hline Vasopressor administration (septic shock); & $1.06(0.47-2.39)$ & ns \\
\hline CVP measurement (septic shock); & $1.18(0.55-2.56)$ & ns \\
\hline \multicolumn{3}{|l|}{ 28-day hospital mortality } \\
\hline Non-compliant versus Fully-compliant & $1.95(0.81-4.69)$ & ns \\
\hline Partially-compliant versus Fully-compliant & $1.24(0.44-4.32)$ & ns \\
\hline Lactate measurement; & $1.04(0.57-1.92)$ & ns \\
\hline Collect blood for hemocultures before antibiotics; & $0.42(0.23-0.76)$ & 0.003 \\
\hline Broad spectrum antibiotics administration (first 3-h); & $0.79(0.43-1.46)$ & ns \\
\hline Fluids (20 - $30 \mathrm{~mL} / \mathrm{kg}$ of crystalloids or equivalent) & $0.70(0.38-1.33)$ & ns \\
\hline Vasopressor administration (septic shock); & $0.86(0.39-1.88)$ & ns \\
\hline CVP measurement (septic shock); & $0.95(0.45-1.98)$ & ns \\
\hline
\end{tabular}

CVP: central venous pressure; RR: relative risk; $\mathrm{Cl}$ : confidence interval; ns: non significant.

The site of origin of the infection varied among the compliance groups. The FC group is almost exclusively composed by respiratory and abdominal CAl, while the NC groups these represent more balanced numbers between both CAl. These disparities might indicate different patient approaches by different medical specialties. The abdominal CAl arriving to the ED are, in their majority, usually first observed by surgeons while the respiratory CAI are first observed by internists with a possible increased awareness to the SSC guidelines. The information regarding the first observing specialist was not extracted from the patient files so no conclusion can be drawn.

Finally, the strong association between the compliance of simple clinical measures (processes) and the 28-day hospital mortality (outcomes) of the treated patients makes the assessment of processes an interesting, cheaper, and easier way to monitor sepsis treatment performance in hospitals. When applied to the multiple hospitals, it could make comparing performance between hospitals more feasible. Process measures being less resource intensive, and more immediate to obtain, are more appealing for the caregivers (doctors, hospitals), while the outcome measures, while more laborious, and are more interesting from a patient point of view. Because of the rigorous definition of the process parameters its measure is not influenced by the sample characteristics. The same is not true for outcome measures, which can be affected by many confounders like the severity of disease or the patient comorbidities. ${ }^{19}$ The sample in study represents the CAI-derived SS/SC patients originated mainly from the ED during a 12 month period. This allows us to exclude possible seasonal variation biases. Nonetheless our data gathering methodology necessarily excluded some patients that where successfully treated in the ED with good responses to early therapy, without the need of being transferred to IICU. These non-visible cases could work as a bias against the treatment.

\section{CONCLUSIONS}

In conclusion in this observational study, we found a low compliance with the sepsis resuscitation bundle recommended by the SSC 2008 guidelines. Nonetheless, compliance with the SSC6 represented a decrease in IICU and 28-day hospital mortality for these patients. Due to this potentially large beneficial effect of the sepsis resuscitation bundle, it is mandatory that institutional actions are taken to make sure that processes like the Green line of sepsis are effectively implemented in Portuguese hospitals. Because of the close relationship between bundle compliance and survival, a continuous monitoring similar the one we did could be used as an effective quality indicator. Additionally our results emphasize the need for a more agile collaboration between the emergency medicine and the intensive medicine professionals.

To our knowledge this is one of the few studies analyzing the SSC bundle compliance outside the ICU environment. Our results add to the current consensus 
that the simultaneous use of a group of evidence-based interventions conduces to better patient care with lower mortality.

\section{OBSERVATIONS}

This work was completed in the Intensive and Intermediate Care Unit (IICU) in the Trás-os-Montes e Alto Douro Hospital Center, EPE (CHTMAD), Vila Real, Portugal. It was the result of the $6^{\text {th }}$ year final work for obtaining the Degree in Medicine - Health Sciences School, Minho University, Braga, Portugal.

\section{PROTECTION OF HUMANS AND ANIMALS}

The authors declare that the study design was approved

\section{REFERENCES}

1. Bone RC, Balk RA, Cerra FB, Dellinger RP, Fein AM, Knaus WA, et al. Definitions for sepsis and organ failure and guidelines for the use of innovative therapies in sepsis. The ACCP/SCCM Consensus Conference Committee. American College of Chest Physicians/Society of Critical Care Medicine. Chest. 2009;136:e28.

2. Vincent JL, Sakr Y, Sprung CL, Ranieri VM, Reinhart K, Gerlach H, et al. Sepsis occurrence in acutely III patients investigators. Crit Care Med. 2006;34:344-53.

3. Póvoa PR, Carneiro AH, Ribeiro OS, Pereira AC, Portuguese Community-Acquired Sepsis Study Group. Influence of vasopressor agent in septic shock mortality. Results from the Portuguese CommunityAcquired Sepsis Study (SACiUCI study). Crit Care Med. 2009;37:410-6.

4. Dellinger RP, Carlet JM, Masur H, Gerlach H, Calandra T, Cohen J. Surviving Sepsis Campaign guidelines for management of severe sepsis and septic shock. Crit Care Med. 2004;32:858-73.

5. Marshall JC, Dellinger RP, Levy M. The Surviving Sepsis Campaign: a history and a perspective. Surg Infect. 2010;11:275-81.

6. Dellinger RP, Levy MM, Carlet JM, Bion J, Parker MM, Jaeschke R. Surviving Sepsis Campaign: international guidelines for management of severe sepsis and septic shock: 2008. Intensive Care Med. 2008;34:1760.

7. George F. Circular Normativa da DGS - 6/1/2010 sobre a criação e implementação da Via Verde da Sepsis a todas as Unidades do SNS. Lisboa: DGS; 2010.

8. Leite H, Dias AP, Gonçalves L, Marques A, Esteves F. Epidemiologia da Sepsis no $\mathrm{SCICl}$ - O Impacto da "Surviving Sepsis Campaign". O CHTMAD em Revista. 2010;2:116-21.

9. Levy MM, Pronovost PJ, Dellinger RP, Townsend S, Resar RK, Clemmer TP, et al. Sepsis change bundles: converting guidelines into meaningful change in behavior and clinical outcome. Crit Care Med. 2004;32:S5957 .

10. Martin-Loeches I, Levy MM, Artigas A. Management of severe sepsis: advances, challenges, and current status. Drug Des Devel Ther. 2015;9:2079-88.

11. Cardoso $\mathrm{T}$, Carneiro AH, Ribeiro $\mathrm{O}$, Teixeira-Pinto A, Costa-Pereira A. Reducing mortality in severe sepsis with the implementation of a core 6-hour bundle: results from the Portuguese community-acquired sepsis study (SACiUCI study). Crit Care. 2010;14:R83.

12. Palricas A. Avaliação dos meios de implementação da Via Verde de Sépsis em hospitais portugueses. Covilhã: Universidade da Beira by the local Health Research and Ethics Committee and constructed in accordance to the Helsinki Declaration of the World Medical Association.

\section{DATA CONFIDENTIALITY}

The authors declare having followed the protocols in use at their working center regarding patient's data publication.

\section{CONFLICTS OF INTEREST}

The authors have no conflict of interest to disclose.

\section{FUNDING SOURCES}

No funding was attributed to this work.

Interior; 2013. p. 72.

13. Ferrer R, Artigas A, Levy MM, Blanco J, González-Díaz G, GarnachoMontero J, et al. Improvement in process of care and outcome after a multicenter severe sepsis educational program in Spain. JAMA. 2008;299:2294-303.

14. Doerfler ME, D'Angelo J, Jacobsen D, Jarrett MP, Kabcenell Al, Masick KD, et al. Methods for reducing sepsis mortality in emergency departments and inpatient units. Jt Comm J Qual Patient Saf. 2015;41:205-11.

15. Resar R, Pronovost P, Haraden C, Simmonds T, Rainey T, Nolan T. Using a bundle approach to improve ventilator care processes and reduce ventilator-associated pneumonia. Jt Comm J Qual Patient Saf. 2005;31:243-8.

16. Levy MM, Dellinger RP, Townsend SR, Linde-Zwirble WT, Marshall JC, Bion J, et al. The Surviving Sepsis Campaign: results of an international guideline-based performance improvement program targeting severe sepsis. Intensive Care Med. 2010;36:222-31.

17. Gao F, Melody T, Daniels DF, Giles S, Fox S. The impact of compliance with 6-hour and 24-hour sepsis bundles on hospital mortality in patients with severe sepsis: a prospective observational study. Crit Care. 2005;9:R764-70.

18. Memon JI, Rehmani RS, Alaithan AM, El Gammal A, Lone TM, Ghorab K, et al. Impact of 6-hour sepsis resuscitation bundle compliance on hospital mortality in a Saudi hospital. Crit Care Res Pract. 2012;2012:273268.

19. Zambon M, Ceola M, Almeida-de-Castro R, Gullo A, Vincent JL. Implementation of the Surviving Sepsis Campaign guidelines for severe sepsis and septic shock: we could go faster. J Crit Care. 2008;23:45560.

20. Weinstein MP, Murphy JR, Reller LB, Lichtenstein KA. The clinical significance of positive blood cultures: a comprehensive analysis of 500 episodes of bacteremia and fungemia in adults. II. Clinical observations, with special reference to factors influencing prognosis. Rev Infect Dis. 1983;5:54-70.

21. Kumar A, Roberts D, Wood KE, Light B, Parrillo JE, Sharma S, et al. Duration of hypotension before initiation of effective antimicrobial therapy is the critical determinant of survival in human septic shock. Crit Care Med. 2006;34:1589-96.

22. Borges N, Kennedy C, Cruz A, Patel B, Williams E. Choosing time zero critically affects quality performance metrics in pediatrics sepsis. Crit Care Med. 2015;43:S236-7. 